\title{
Computer Simulation and Analysis of Curl Mechanism for Cold Rolled Steel Strip
}

\author{
Peng Zeng ${ }^{1,2, a}$, Jiangang $\mathrm{Yi}^{1, \mathrm{~b}^{*}}$ and Li Zhao ${ }^{3, \mathrm{c}}$ \\ ${ }^{1}$ Hubei Key Laboratory of Industrial Fume \& Dust Pollution Control, Jianghan University, Wuhan, \\ China \\ ${ }^{2}$ School of Mathematics and Computer Science, Jianghan University, Wuhan, China \\ ${ }^{3}$ Dongfeng Honda Automobile Co. Ltd., Wuhan, China \\ a mytemp518@126.com, byjg_wh@yeah.net, ${ }^{\mathrm{c}} \mathrm{zl} @ w d h a c . c o m . c n$
}

\begin{abstract}
Keywords: Curl Mechanism, Steel Strip, Computer Simulation, Analysis and Optimization
Abstract. Curl mechanism in cold rolled steel strip coiler is the key part for strip curling. This paper established the 3D model of cold rolled steel strip coiler. Based on it, the structure of the curl mechanism is designed and analyzed. The stress distribution of the drum and the drum shaft in the curl mechanism are simulated by using finite element analysis. According to the given working parameters, the bending moment and the torque of the drum shaft are calculated by theoretical method and numerical simulation. The results provide guidance for the repair and maintenance of the curl mechanism in cold rolled steel strip coiler.
\end{abstract}

\section{Introduction}

As industrial auxiliary equipment, cold rolled steel strip coiler is widely used in metallurgical automation production line. Through the rotation of the drum of the curl mechanism in the cold rolled steel strip coiler, the cold rolled steel strip processed in the previous step is curled for treatment and transportation of the next step [1]. With the increase needs of the plate steel market, the quality of cold strip is highly required [2]. The indexes in the strength, hardness, flatness, smoothness, stability and so on are becoming tougher and current technology and processing methods have become increasingly difficult to meet the needs of industrial production [3]. At present, the study of how to improve the quality of machining, forming curl has becoming the hot topic in the world steel rolling machinery field [4].

In the curling process of cold strip curl, the work performance of curl mechanism is one of the key factors determining the quality of product. Curl mechanism is the core of the whole structure of coiler. When the cold strip is coiled, it is demanded to ensure that the coiled strip tension is constant. In order to realize the constant tension curling, it is necessary to realize the radial motion of curling mechanism for achieving the action of the curl component expansion and condensation so as to control strip tension. Therefore, the study of cold strip coiling mechanism has a very important significance for improving product performance [5].

\section{The Working Principle of Curl Mechanism}

The main part of the curling mechanism includes the feeding roller, the drum, the wrapper roll and the unloading device. Among them, the feeding roller is used for rolling belt head and curving it downward into the coiler. When the strip tail is left from roller, the curling tension is established. In order to make the smooth feeding for steel strip coiler, the upper feeding roller diameter is usually $800 \sim 950 \mathrm{~mm}$, and has a relative offset of 50 300 $\mathrm{mm}$ or offset 20 degree along the strip direction. The lower feeding roller diameter is usually $400 \sim 500 \mathrm{~mm}$. The wrapper roller is used for pressing strip and guiding it for the next curl step. The unloading device is used for dragging strip and removing it from the coiler.

Drum is the key component of the curl mechanism. The following three reasons determine the high complexity of the curl part. First, the strip steel curled is usually in dozens of tons for curl mechanism. 
Second, to meet the needs of production and improve production efficiency, the curl velocity is very large under the work state. Third, the diameter of the drum must be reduced for removing strip steel while the radial force is pressed around it. Based on the above reasons, good cooling and lubricating system are necessary to meet the need of high speed operation and friction heat generation when the curling function in the curl mechanism is generated.

\section{Modeling of the Curl Mechanism}

In the process of curly, the whole action can be divided into the preparation stage, beginning stage, stable stage, work stage, end stage and unloading stage. During the preparation stage, cold steel strip is moved to the tail of the rolling mill, waiting to enter the curl mechanism for winding up. In the beginning stage, the steel strip is moved to the curl roller under the action of the guide wheel. In the stable stage, the constant tensile stress between the coiler and the mill is built. In the work stage, the strip is curled freely in high speed on the drum. At the end of the stage, the curl speed declines generally. In the unloading stage, the curl mechanism stops, waiting for the unloading device removing the steel strip from the strip coiler.

The hydraulic control part in the curl mechanism provides hydraulic pressure to the hydraulic oil cylinder to make the single piston rod bidirectional rectilinear motion. The left end of the pull rod is connected with the piston rod with a fixed screw thread. The curl part comprises a cambered plate, a lining plate, a baffle plate, a wedge, a sleeve, a drum shaft, as in Figure 1. The pull rod works under the bidirectional linear motion driven by the hydraulic cylinder. At the same time, the pull rod and the sleeve are connected. Through the mutual movement between the wedge surface and the fan-shaped plate surface, the expansion and contraction function of the drum is achieved.

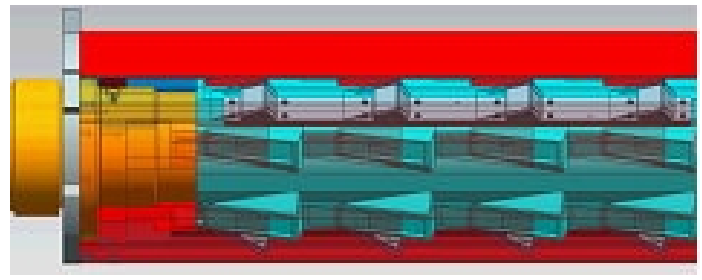

Fig. 1: The drum in the curl mechanism

\section{Analysis of the drum shaft}

As the main stressed component, the drum shaft has the function of driving drum to curl the steel strip. Meanwhile, the stress pressed on the drum is led to the drum shaft. If the drum shaft is damaged, it is easy to take accident. Therefore, in the work process, it is important that no failure danger of the drum shaft is occurred. In order to analyze stress distribution, the three dimensional model of drum shaft is established, as shown in Figure 2. In Figure 2, $F_{t}, F_{r}$ and $F_{a}$ are the horizontal radial force, the radial vertical force and the axial force at the drum shaft maximum force point. $\mathrm{F}_{\mathrm{NH} 1}$ and $\mathrm{F}_{\mathrm{NH} 2}$ are the support forces at the shaft ends. Respectively, $\mathrm{F}_{\mathrm{NV} 1}$ and $\mathrm{F}_{\mathrm{NV} 2}$ are the vertical supporting force. $\mathrm{F}_{\mathrm{NV} 1}$ is the axial transmission force, $\mathrm{T}$ is the transmission torque. Figure 3 is the drum shaft bending moment analysis chart. According to the parameters given in Table 1, using the correlation formula of theoretical mechanics and material mechanics, the drum shaft stress value and distribution can be calculated, and the intensity and rigidity can be checked. 


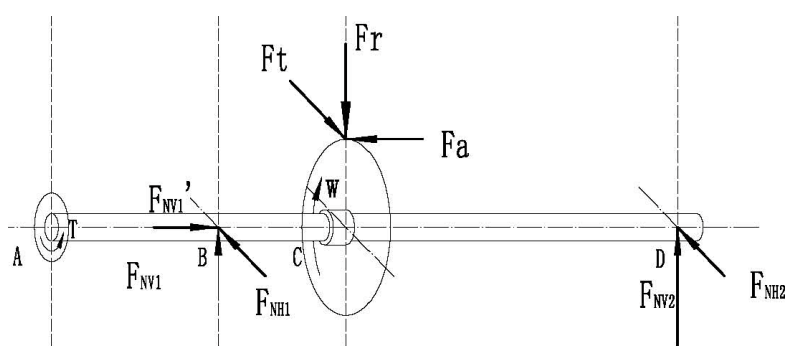

Fig. 2: Force analysis of drum shaft

Table 1: The working parameters

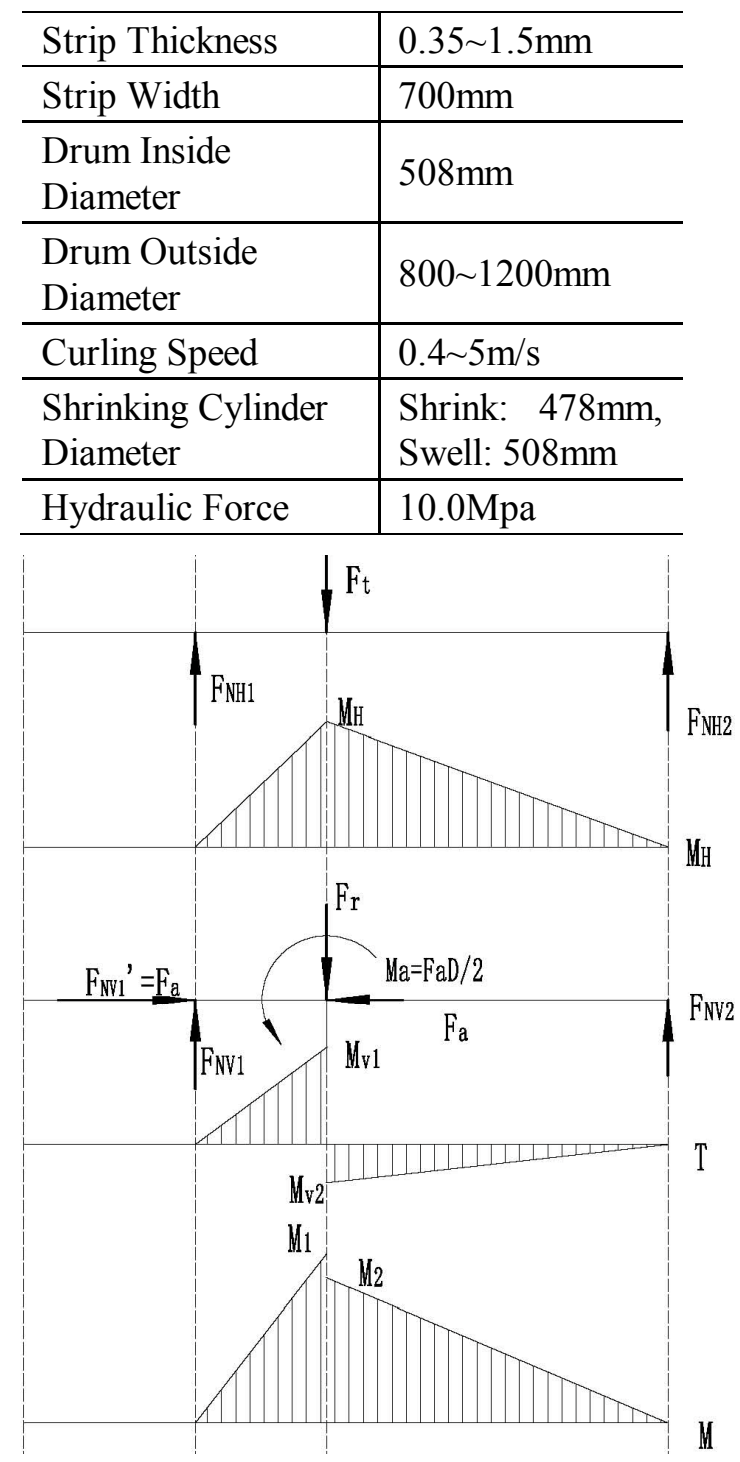

Fig. 3: Bending moment analysis

According to Figure 3, assuming $\mathrm{M}$ is the bending moment, then:

$$
M=\sqrt{M_{H}^{2}+M_{V}^{2}}
$$

From Equation (1), the bending moment can be calculated, while $\mathrm{T}$ is simplified as a constant value. Assume $\alpha$ is the equivalent coefficient, $W$ is the section bending modulus, according to Equation (2), the calculation stress of the drum shaft can be calculated.

$$
\sigma_{c a}=\sqrt{\left(\frac{M}{W}\right)^{2}+4\left(\frac{\alpha T}{2 W}\right)^{2}}=\frac{\sqrt{M^{2}+(\alpha T)^{2}}}{W}
$$




\section{Analysis of the drum stress}

For cold steel strip coiler, the diameter selection of the drum should follow the general design principle that the inner layer strip does not become plastic deformation during the work process. In addition, the curling process of the cold steel strip is not an independent process. Considering the link up with other processes, the drum diameter cannot be chosen too small or too large. When the strip thickness range vary greatly, the scheme of changing drum diameter or using of additive sleeve or replaceable sleeve should be adopted according to the thickness of transformation process requirements. This will prevent plastic deformation or in small diameter drum or the collapse because the inner hole is too large.

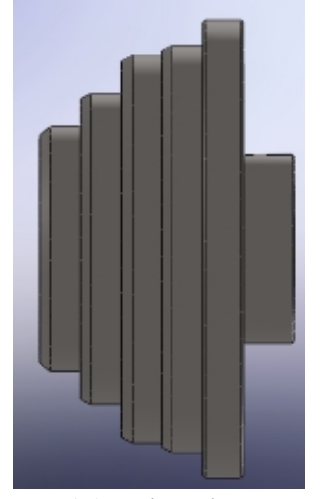

(a) The drum

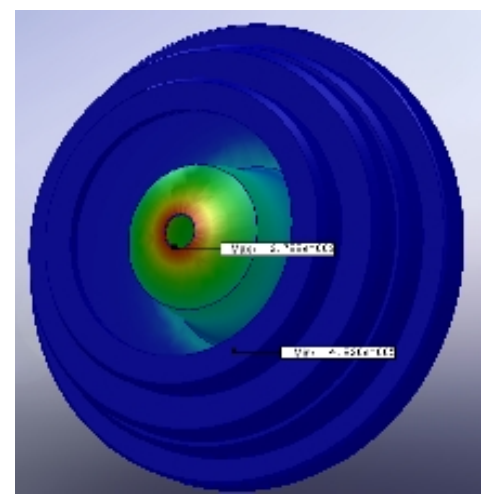

(b) The stress distribution

Fig. 4: Analysis of the drum stress

The calculation of the drum radial pressure not only is the prerequisite for the hydraulic cylinder thrust force and the drum strength, but also is directly related with the coiling quality. According to the simulation, the drum radial pressure is related to the coil stiffness, the interlayer sliding with friction, the coiling tension and coil diameter and so on. Because the above problems are very difficult in the theoretical analysis, this paper applies the approach of finite element simulation, as shown in Figure 4. According to the working parameters Table 1, it is found from simulation that the maximum stress distribution is in connection with the shaft of the drum. Therefore, in the daily repair process, we should strengthen the inspection of the connection position of the drum and the shaft.

\section{Conclusions}

The performance of the curl mechanism in cold rolled steel strip coil is the key factor for product quality. In actual production, it is important to pay attention to the working state of the curl mechanism. By using theoretical analysis, computer simulation and finite element simulation method for the curling process of cold rolled steel strip coiler, this paper analyzed the stress distribution of the drum and the drum shaft, which provide guidance for the repair and maintenance of the curl mechanism.

\section{Acknowledgment}

This work is supported by Industry-university-research project of Wuhan Education Bureau (Granted No: cxy02) and the open project of Hubei Key Laboratory of Industrial Fume \& Dust Pollution Control (Granted No: HBIK2014-05), China. The authors also gratefully acknowledge the helpful comments and suggestions of the reviewers, which have improved the presentation.

\section{References}

[1] Ulrika Nyström K G. Numerical studies of the combined effects of blast and fragment loading. International Journal of Impact Engineering, 36(2009), 995-1005. 
[2] Youyun Li S L. A finite element model based on statistical two-scale analysis for equivalent heat transfer parameters of composite material with random grains. Applied Mathematical Modelling, 33(2009), 3157-3165.

[3] Zhou Linren, Ou Jinping. Study of parameters selection in finite element model updating based on parameter correction. ICIC Express Letters, 4(2010), 1831-1837.

[4] Key Nicole L. Compressor vane clocking effects on embedded rotor performance. Journal of Propulsion and Power, 30(2014), 246-248.

[5] Yi Jiangang. Modelling and Analysis of Step Response Test for Hydraulic Automatic Gauge Control. Strojniški vestnik - Journal of Mechanical Engineering, 61(2015), 115-122. 